\title{
'THE MIDDLETON MYSTERY: AN ADVENTURE AT BELSAY HALL' INTERPRETING HERITAGE THROUGH THE DESIGN AND DEVELOPMENT OF A COMPUTER GAME
}

Lynne Minett

Education Manager, North of England

English Heritage

Learning Department

37 Tanner Row

York, YO1 6WP

United Kingdom

Lynne.Minett@english-heritage.org.uk

http://www.english-heritage.org.uk

\author{
Dr Carl J Gavin \\ Managing Director \\ Lateral Visions Software Company \\ 3E Wavertree Boulevard South \\ Wavertree Technology Park \\ Liverpool, L7 9PF \\ United Kingdom \\ carl.gavin@lateralvisions.co.uk \\ http://www. lateralvisions.co.uk
}

\begin{abstract}
English Heritage has been exploring an approach to interpreting heritage using computer games. Instead of the learning resulting from gameplay inherent within an existing computer game, the learning and interpretation is generated through the holistic process of designing and developing a computer game. This paper presents one such project, 'The Middleton Mystery - An Adventure at Belsay Hall'. Students at Ashington Community High School designed a computer game set in a virtual version of Belsay Hall, Castle and Gardens in Northumberland. The objective was to use computer games technology to interpret Belsay's history in a way that young people would find appealing: to increase knowledge and understanding about Belsay Hall and to change attitudes and values about heritage in an inspirational, creative and enjoyable way.
\end{abstract}

\section{INTRODUCTION}

'The Middleton Mystery' project was delivered as part of the 'Picture House' contemporary arts exhibition (3 May-31 September 2007) at Belsay Hall, Castle and Gardens in Northumberland. English Heritage wanted to develop its work with a new audience by targeting young people, engaging a group at risk of exclusion from mainstream education in their local heritage and encouraging new visitors to the site. The brief was to use a computer game to interpret Belsay's history in a way that young people would find appealing.

Why develop a computer game? A computer game presents a virtual environment that players interact with in order to achieve a goal or set of goals. In recent years, the use of computer games for non-entertainment purposes ('Serious Games') has become popular. Serious Games make use of the engagement, fun and competition that computer games provide to encourage users to continue the learning experience. They become so engrossed in playing the game that they do not notice the amount of information, skill or knowledge that they are learning whilst playing.

By selecting an outcome that tapped into the students' enthusiasm for computer games that are now so integral to young people's cultural lives, English Heritage were able to promote active learning as well as motivate the individuals involved. 
'The Middleton Mystery' is the game that the young people developed by forming their own production company the 'Mean Machine'. They used the inspiration of the medieval castle, 19th-century hall and quarry garden to create a fictional quest-based adventure game. Players meet characters based on real people who lived and worked at Belsay and find imaginary treasures brought back from Charles Monck's Grand Tour. The students created the game design and filmed themselves as historical characters.

The students' game design and specifications were built by Lateral Visions, a software development company specialising in applying computer games technology to education and business applications. English Heritage staff, ISIS Arts, and games artist Steve Manthorp, led creative workshops with the students providing the basis for the stories which steered the direction and content of the game.

The students launched a test version of the game on 17 July 2007 at an event attended by their teachers, family and individuals from arts and heritage across the North East of England. The Middleton Mystery Room - a newly designed area for young people, was created in addition to marketing materials and a website. The game was played by visitors to the site who were invited to leave feedback. Community groups were also invited to participate in this feedback process. Visitor feedback steered the final direction of the game which was installed at Belsay on 1 October 2007.

\section{PROJECT AIMS}

The aims of the project were:-

- To encourage and increase participation by young people at risk of exclusion at Belsay Hall

- To increase knowledge and understanding about Belsay Hall

- To develop and realise ideas through creative, discursive, social and specific IT/programming skills

- To change attitudes and values about the heritage

- To stimulate inspiration, creativity and enjoyment

- To change behaviours and aid re-integration into mainstream education system

\section{INITIATING THE PROJECT}

A steering group was formed to manage the project. The steering group consisted of individuals from the partnering organisations: English Heritage, Lateral Visions Software Company, ISIS Arts and Manthorp ACT, and met monthly to make key decisions and lead the project.

Schools local to Belsay Hall, and interested in arts projects, were contacted. Eight young people from the 'Success Makers' group at Ashington Community High School were subsequently recruited for the project. This group is part of the school's Learning Support Unit and consists of students who are at risk of exclusion from mainstream education. Ashington Community High School supports the use of the arts in education, particularly for students who have difficulty in more mainstream, academic aspects of the curriculum; for this reason, the school was invited to take part in the project.

\section{THE PROJECT}

A project timetable was established by the steering group which involved a range of workshops intended to develop the design and content of the game. A launch date of 17 July 2007 was set and advertised as part of the Picture House programme. A decision 
was made to phase the introduction of the game on-site by creating a demonstration version in time for the launch date (levels one and two featuring the hall and quarry gardens) which could be used to gain feedback from general visitors over the school summer holidays. The final version (including the hall, quarry garden, castle and cellars) was installed on 2 October 2007.

Session One (Ashington Community High School), 27 March 2007 - the young people were introduced to the key concepts behind computer games, and discussed different types of games, how they work and successful features. They were introduced to computer games created by Lateral Visions and Steve Manthorp. Following this, they worked in pairs to create a 'paper pilot' of a game.

Session Two (Belsay Hall), 16 April 2007 - this session included an icebreaker for the young people, followed by an introduction to the hall. The young people fed back to the group their impressions of the hall, and completed a treasure hunt. They were introduced to oral history as a form of historical record, and listened to some recordings. They were given the opportunity to digitally photograph features that they found interesting, which was a new experience for the majority of them. They had a tour of rooms that are usually inaccessible to the public and experimented with possible narratives for the game, with the aid of props. In written evaluation at the end of the session, the behind-the-scenes tour and the use of digital cameras were widely reported as being very well received.

Session Three (Ashington Community High School), 24 April 2007 - the group briefly reviewed their photographs and visit to Belsay Hall. The concept of working as a team was impressed upon them. Following a brainstorming session, a name for their team and game was decided and first drafts of logos were created. Most of the group seemed to particularly enjoy these tasks. An initial website holding page was created for the 'Mean Machine' production company and the group developed ideas for the narrative and characters of the game.

Session Four (Belsay Hall), 1 May 2007 - each member of the group chose a character and used their knowledge of Belsay Hall to devise hiding places for their treasure. They devised a clue that their character would communicate to the player, and wrote a short script. These scripts were shared with the group, who discussed the clues.

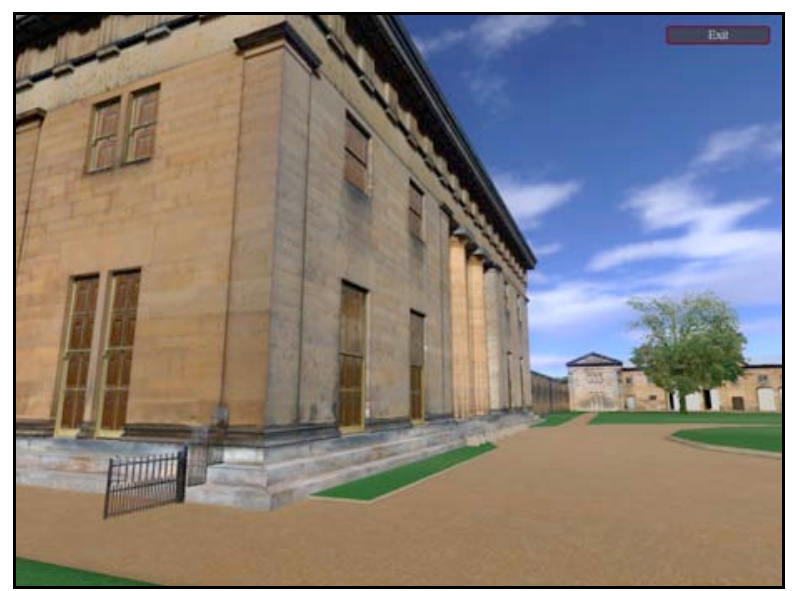

Figure 1. Screenshot - Level 1 - Outside Belsay Hall

Session Five (Belsay Hall), 22 May 2007 - the young people were filmed delivering their scripts in costume. This was approached with great enthusiasm by the group, who by now expressed greater levels of confidence in front of the camera. As one student 
was absent due to illness, a part had to be rewritten and delivering this unexpected performance was a very daunting task for the pupils involved. It was decided that the absent student would be filmed at school upon her return, which allowed the whole group to appear in the final game. As well as being filmed during the session the young people thought about designs and wording for invitations to the launch.

Session Six (Belsay Hall), 19 June 2007 - students were introduced to a test version of level one of the Middleton Mystery. They saw the results of their ideas and artwork for the first time and completed a feedback form that encouraged them to suggest amendments. The opportunity also arose for the participants to be filmed again as the initial filming presented a challenge to one of the students who struggled with the literacy element of reading from a script.

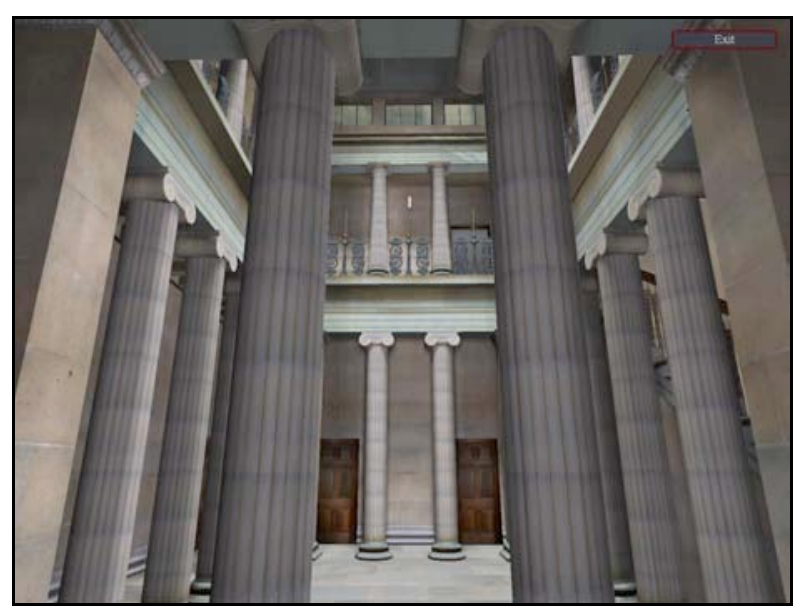

Figure 2. Screenshot - Level 1 - Inside the Hall

The Launch (Belsay Hall), 17 July 2007 - approximately sixty people attended the launch. Ashington Community High School brought fifteen teachers, the students and family members to celebrate the success of the project. A buffet lunch was served and after short formal speeches by English Heritage and the Head Teacher, each student was presented with a goody bag containing a family pass to Belsay Hall, a badge saying 'I Made the Middleton Mystery' and a framed, signed photograph of the group. One of the students invited the assembled company into the Middleton Mystery Room where they were treated to a preview of the game by the students who demonstrated it proudly. The sense of pride and ownership felt by the 'Mean Machine' game development company was very evident. A student commented that it was 'mint' to be involved and a number thanked the organisers for their hard work.

The diverse nature of organisations represented at the event indicated the high level of interest in the project. Guests included staff and board members from partnership organisations, those involved in the Picture House exhibition, local authority Art Development Officers, a School Improvement Officer from Northumberland County Council, representatives from art organisations such as Northern Film and Media, Creative Partnerships Northumberland and Theatre Sans Frontiere based in Hexham.

A number of PR opportunities were developed with local press, games magazines and sector publications, including various North East papers, TES Online, PC Zone, Edge Magazine, BBC Look North, BBC Radio Newcastle, Heritage Today, Museums Journal, Heritage Counts, and Heritage Learning.

15,000 postcards were created and distributed to local schools and English Heritage 
sites offering reduced-priced admission to Belsay during the summer holidays.

A micro site was created from the Picture House website which served as a marketing tool, but also to disseminate details of the project and download a demonstration version of the game.

Youth Group Visits - following the launch, the feedback phase began. Invitations were sent to several local youth groups inviting them to meet the game designers, trial the game and provide feedback. The groups looked around the hall and gardens before having lunch and coming back to discuss their comments about the game and any further ideas they had. The comments that the game could be a bit 'scarier' were taken on board in the finalising of levels three and four - the castle and cellars.

\section{THE MIDDLETON MYSTERY GAME}

The main element of the project in terms of materials delivered was the creation of the computer game. As previously identified, the young people led the creative process within clearly defined boundaries such as avoiding the use of violence and weapons. The young people responded to the role of forming their own production company and this gave them a sense of ownership of the product.

The game contains four levels relating to different locations on-site. It contains voices of the young people and includes them dressed in role as characters from Belsay's history. The player explores the site looking for 'speaking characters' who then direct the player to find a series of objects. Once collected, the player is given a code which they are instructed to take to the site shop. Upon giving the code, they are presented with a free pin badge saying 'I Solved the Middleton Mystery'.

The game is played in a room on site which was previously the site shop. Project budget was spent purchasing PCs, game pad controllers, tables and soft furnishings to decorate the room in a style appealing to young people.

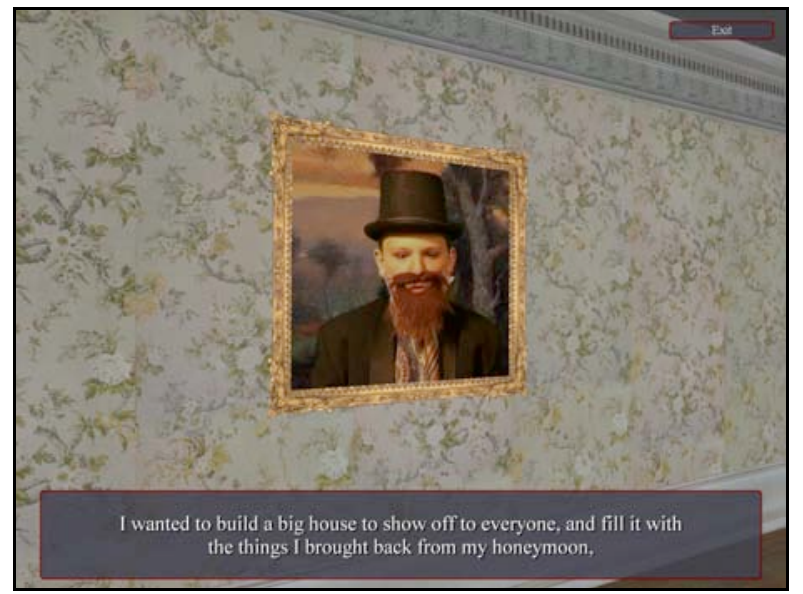

Figure 3. Screenshot - Level 1 - Meeting Sir Charles Monck

\section{EVALUATION METHODOLOGY}

A variety of evaluation methods were used to track changes in attitudes, skill levels and general engagement with the project. It was anticipated that asking students to write their feedback could prove difficult for some; therefore writing was kept to a minimum.

Teaching staff were canvassed for their views, particularly with reference to the confidence and engagement levels of the students. Observations and feedback from 
other adults involved in the workshops (the games artist, game developers, education co-ordinator and heritage education worker) were also sought.

Students were interviewed at the beginning and end of the project and asked questions about heritage, computer games and their attitude to being involved in the project. The results were transcribed and analysed to determine whether any significant changes had taken place.

Students were encouraged to offer verbal or written feedback throughout the project, as their interests guided the development of each workshop session. They were asked to complete a simple written evaluation of the heritage workshop at Belsay Hall.

\section{OBSERVATIONAL REFLECTIONS}

The project was clearly very popular with the young people. The group's teacher commented that despite some displays of disinterest in the first few sessions, the fact that $100 \%$ of the group continued to attend sessions shows a very strong engagement in the project, it being one of the best-received projects the group have undertaken.

Since their involvement in the project, there has been a notable improvement in the general behaviour of the group. This was particularly evident during sessions at Belsay Hall, where they frequently listened and waited their turn to speak (something which had rarely happened during school sessions a few weeks previously). Their selfconfidence in front of the video camera also improved dramatically over time, when many had described being photographed as the least enjoyable aspect of the visit.

The concentration level of the group was more sustained and they seemed to enjoy learning in a different environment from school.

The most popular activities during sessions seemed to involve exploring the site, and particularly going into rooms that are usually closed to the public. Many commented that they enjoyed having the freedom to explore the site. Reading and writing tasks were not popular and rarely approached with much confidence. Although many of the group expressed a lack of confidence in their artistic abilities, they clearly enjoyed the task of designing a logo for their gaming company - a topic that they had recently learned about in school. A few of the group further researched it during their break and enthusiastically shared their findings with the group, planning to continue working on their designs at home. In general, tasks that invited creative input into the game (for example, devising characters and narratives) were met with considerable enthusiasm, and the group responded well to the expectation to work as a team.

The group's change in attitude towards being filmed is a strong indicator of growing self-confidence. Although they hid from cameras at the first session, within a few weeks they were able to deliver a scripted performance to a video camera. This was a particular achievement for one student who has great difficulty with reading. This task was approached with enthusiasm and the group greatly enjoyed dressing up and took the preparations and learning of lines seriously (one student, for example, had been practicing his German accent with his drama teacher).

The project has engaged the young people and seems to have given many of them a new-found interest in education. For example, a particularly disengaged student, who is at high risk of expulsion, was pleased to share with an adult his knowledge of the different birds and plants found in the gardens.

Many of the group commented that their game would be likely to attract visitors to the site. They also acknowledged that they would have improved their historical knowledge by the end of the game, and frequently, without prompting, shared their 
knowledge of the site with adults who had not visited before. When writing short scripts for different characters, it was clear that they had remembered information such as the living conditions and lifestyles of people who would have lived at Belsay Hall. They also demonstrated an unprompted historical awareness by discussing the need to avoid the use of slang or modern language in their scripts.

Attendance figures of those participating at workshops and the launch reflected the degree of involvement and enjoyment in the project, and an indication of the sense of ownership and pride felt by the students about this project.

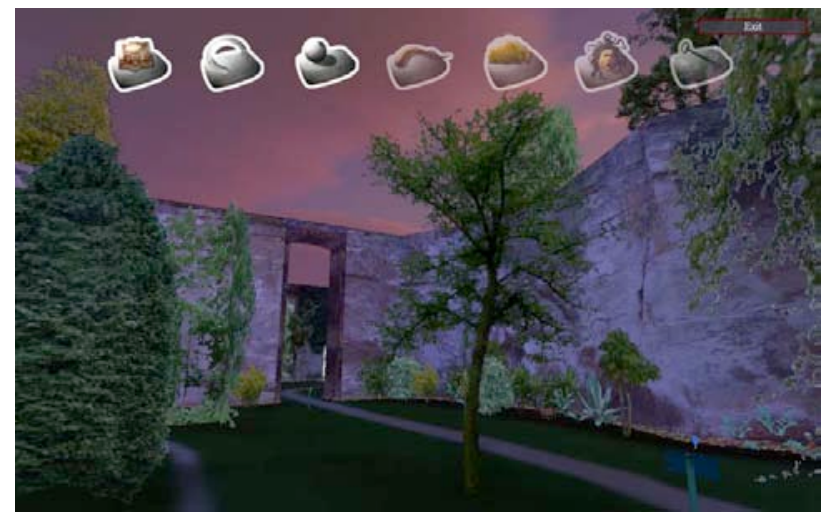

Figure 4. Screenshot - Level 2 - The Quarry Gardens

\section{IMPACT AT BELSAY HALL}

As well as creating a stimulating learning experience for the young people, the project has had a wider impact. The game has enhanced the offer to families and general visitors to Belsay Hall.

There has been very positive feedback from visitors. Impact was measured between 17 July to 1 October 2007 using varied methodology, including feedback cards and analysis of game play statistics collected by the computer games at the site.

The game proved to be very popular with the 9-12 age group. There were a number of negative responses related to the expectation that the game would follow the commercial games format in terms of content and graphics.

A function was added to the website which allowed visitors who had downloaded the game or visited the site to email feedback. Only four feedback forms were received during this period suggesting that this was not a popular way for visitors who had not visited Belsay to leave feedback.

From 17 July to 1 October (77 days) there had been 1499 plays of the game at the Hall - an average of 19.47 plays per day. The average duration of play was 15 minutes, 18 seconds (the shortest duration of play being 4 seconds; the longest duration of play being 82 minutes, 32 seconds).

\section{PROJECT OUTCOMES}

The project delivered in several of the key areas identified:

Local heritage - by taking part in the project the group gained an understanding of their local heritage and the history of Belsay Hall. The evaluation demonstrates that they showed greater awareness of heritage as a result of the workshops and visits.

Heritage, education and access - the project provided an opportunity for the group to gain better access to their local heritage. Prior to their involvement with the project, the group had not visited heritage sites as part of their vocational programme due to the lack 
of sufficient opportunities. The project gave them access to heritage through a focused strategy of varied and stimulating activities designed to appeal to their interests. It encouraged them to think beyond their initial perceptions that 'history is boring' and that heritage can be fun and 'cool'.

The workshops with youth groups, whilst limited did provide an additional activity during the school holidays for local young people.

Promoting access for people from all sectors of society - as a group from a learning support unit with specific behavioural and emotional needs, the young people are not always welcomed when they undertake visits. This project allowed English Heritage to provide a suitable project to engage an under-represented group of learners. It also allowed us to work with a group from a less-affluent community - Ashington is a former coal mining area and has many of the social problems associated with industrial decline. The contrast of visiting rural Northumberland therefore provided a new experience compared with their usual environment.

Promoting knowledge of and interest in heritage by children and young people - the steering group were pleasantly surprised that the group retained a great deal of knowledge about the site and the people who lived there. The archive images, oral histories and behind-the-scenes tour all stimulated their interest and encouraged them to become active learners by exploring the site and using this knowledge for their game.

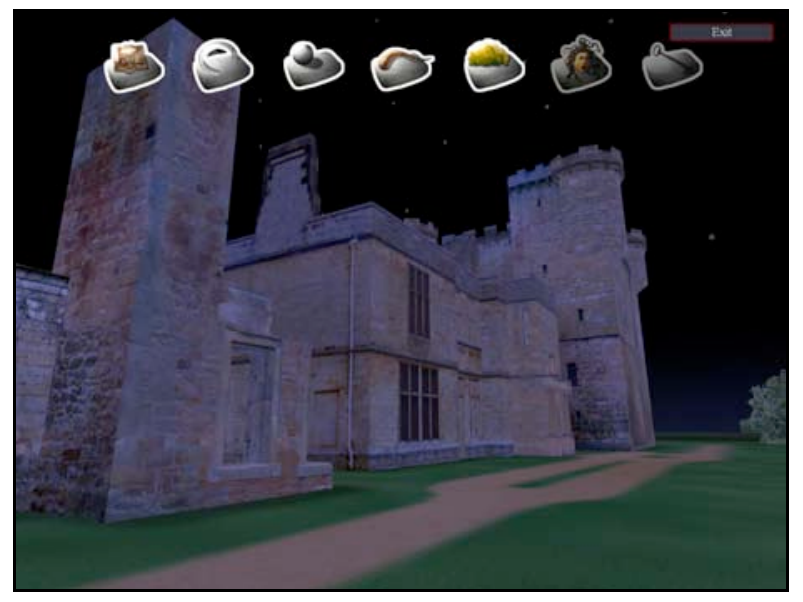

Figure 5. Screenshot - Level 3 - The Castle

\section{LESSONS LEARNT}

Timescales and outcomes - considering some pre-work pending the outcome of the bid helps to minimise the necessary start-up delays when beginning a new project, unforeseen time commitments at this stage resulted in a very tight delivery timetable which although achieved, would not be repeated in future projects.

Working in partnership and defining roles - recruiting the right partners who can deliver to clearly defined roles is essential for smooth communication and successful delivery. Practical issues like VAT registration and financial procedures created delays, in addition to conflicting ways of working between diverse organisations. These areas should be discussed at the outset of future projects to ensure all are clear on their responsibilities. The creation of a steering group would be repeated in the future as it proved an effective means of communicating and making decisions. 
Working with the group - identifying schools to work with and subsequent communication should be through a specified teacher to allow for consistency and to maximise their commitment.

Identifying a fun and interesting outcome which would appeal to the group's interests is vital if seeking to fully engage them with the final product. Despite fears that the group would want to create a violent game, the young people were gently led towards creating a more family-friendly game that would encourage positive behaviours of learning and exploration. Selection of an appropriate outcome and research with the group themselves to define what they would like to create would be repeated.

Appropriate and varied creative tasks, such as devising narratives or characters for the game have been some of the most popular aspects of the project. These have provided a successful model for future work with learners who do not enjoy writing. Such tasks were most successful when their duration did not exceed 30 minutes, as the group found it difficult to concentrate for much longer than this. The group responded well when writing tasks were interspersed with opportunities to move around. Initial sessions consisted of short tasks, whose length was increased steadily over the project, in line with improved concentration.

Undertaking sessions on-site is beneficial as group behaviour is generally better when they are out of the school environment, with frequent opportunities to move around the grounds. Learning in context is also vital; for example, many members of the group seemed to have difficulty engaging with locations if they were not physically there. This demonstrated itself when discussing possible hiding places for treasure they became more enthusiastic and able to formulate many ideas and concepts when in the same location that the game-player would be.

Inviting the young people to devise a team and game name, and to have their names put on the game website afforded them a sense of ownership of the project. This is a theme which could be developed further in light of the current focus on enterprise in the curriculum.

Working with youth groups from the community - Offering sessions at the right time for groups to be interested is key to encouraging them to be involved. Despite our best efforts to contact groups, many did not respond or said their group was too dispersed due to the holiday period. The feedback and involvement from those who visited Belsay Hall was valuable and in future projects should be maximised earlier by planning sessions to fit around the needs of the groups.

Evaluation - creating a focused evaluation strategy incorporating varied methodology yielded good qualitative and quantative data which could be mapped to generic learning outcomes. The young people frequently reported being pleased that the project didn't involve much writing. This is an important factor to consider when working with a group from a Learning Support Unit.

Celebrating success - planning a launch event for projects is important in celebrating the success of the individuals involved. We maximised attendance at the event by scheduling it to take place during the day, with a bus from the school to transport students and their families. Providing rewards such as a signed photograph of the group, and a site pass for a repeat visit was popular and at least one of the individuals has returned with his family who couldn't attend on the day.

Marketing - ensuring that there is a clear area of responsibility for distribution of marketing materials is crucial. The game has been played substantially at the site and has exceeded expectations in terms of its appeal to existing visitors. Site staff have reported it has been very popular with families and general visitors, and as a result of 
this, the game has been advertised to English Heritage members in the handbook and a retail version was produced and made available through the site shop.

The design, copy and production of the launch postcards, the marketing postcards, the on-site leaflets and the game itself created an excessive amount of work for the steering group. Consequently, some tasks were not realised to their full potential. Again, defining roles at the beginning and ensuring there is a designated person responsible for all key milestones is crucial. Phasing delivery of design and print is also key. Working with a large PR agency helped the project achieve good coverage and dissemination.

Integration with the Picture House exhibition - the project was successfully linked with Picture House at Belsay. The inclusion of the Middleton Mystery micro website within the Picture House website is a good example of this.

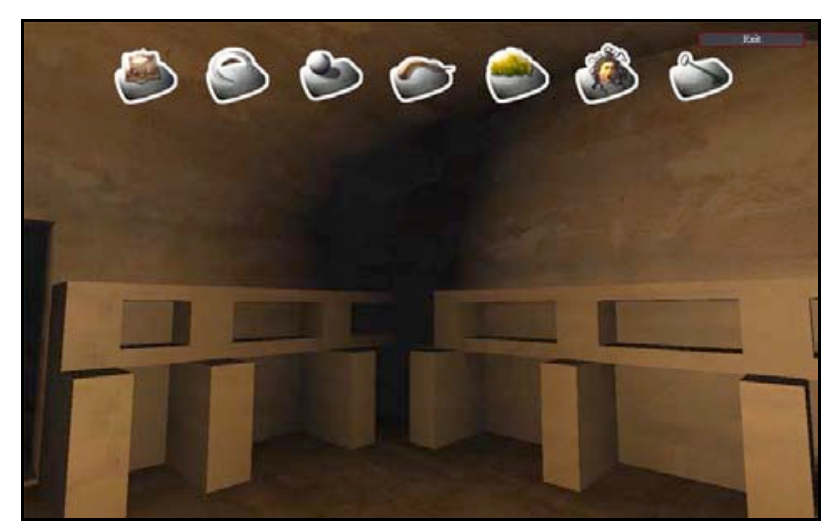

Figure 6. Screenshot - Level 4 - The Spooky Cellars

\section{CONCLUSION}

'The Middleton Mystery' project has successfully engaged young people at risk of exclusion from mainstream education at Belsay Hall by increasing their knowledge and understanding of the site and its history and by developing their creative, social and technological skills. The individuals involved have increased confidence among adults, their peers and in their own abilities. It encouraged them to think beyond their initial perceptions that 'history is boring', helping them realise that heritage can be fun and even 'cool'. They retained a great deal of knowledge about the site and the people who lived there.

In addition, the young people developed a tangible, exciting computer game that educates others about Belsay Hall. The game itself has proved very popular with young people and general visitors at Belsay Hall, encouraging them to learn about the site in a fun and interactive way. The game and the materials produced to promote it have been of a high standard and have raised awareness of the learning potential of heritage sites within the care of English Heritage.

\section{ACKNOWLEDGEMENTS}

Without support from the Heritage Lottery Fund through the 'Your Heritage' grant, this project would not have been possible. 